Pecvnia, 3 (2006), pp. 1-20

\title{
La responsabilidad social corporativa. Su dimensión normativa: implicaciones para las empresas españolas
}

\author{
Eduardo Fuentes Ganzo
}

¿Estamos asistiendo a un proceso de normativización de la Responsabilidad Social Corporativa (RSC)? ¿De ser así, éste tiene especial incidencia en Europa y en España? Y finalmente, si el Estado está incorporando, dentro de sus Corpus normativos, principios de RSC ¿qué consecuencias, implicaciones e impactos económicos tienen para las empresas y para su futuro inmediato?. Estas son las cuestiones fundamentales objeto de análisis en el presente artículo.

Palabras clave: Responsabilidad Social Corporativa; RSC; Regulación Empresa; Legislación consumidores; Leyes medioambientales; Coste Social.
Is a regulatory process of Corporate Social Responsibility (CSR) taking place at the present moment? In that case, what influence does this process have in Europe, and particularly in Spain?, and what economic consequences will it create for the Firms and the Businesses? All these questions are tried to be answered in this paper.

Key words: Corporate Social Responsibility; CSR; Business Law; Consumers regulation; Environmental Laws; Social Cost.

\section{INTRODUCCIÓN}

En los últimos años se manifiesta como plenamente vigente, dentro de la literatura empresarial, la preocupación por el desempeño social y ético de las organizaciones, lo que ha hecho que cobren singular 
La responsabilidad social corporativa. Su dimensión normativa: implicaciones para las empresas españolas

protagonismo las cuestiones de la Responsabilidad Social Corporativa (RSC) -Corporate Social Responsibility (CSR) en el ámbito anglosajón-. Preocupaciones como la presencia y acción de los Stakeholders, las actuaciones e impactos sociales y ambientales de la empresa etc., son, cada vez, objeto de más numerosos estudios y contribuciones.

En esta línea, aunque es lugar común entre la literatura científica admitir, en sede teórica, que la Responsabilidad Social Corporativa -RSC- (Nieto Antolín y Fernández Gago 2004; Fernández Gago 2005 y Bigné et al. 2005) tiene, en su aplicación por la empresa, un carácter voluntario (Nieto Antolín 2005), no se puede ignorar que está sufriendo una importante presión regulatoria, que habrá de ser objeto de tratamiento tanto por las escuelas de economics and law y el institucionalismo económico como por las de management clásico (Cuervo 2003).

Dicho esto, es menester introducir una precisión, obvia para juristas, que no resulta tan evidente para economistas y otros científicos de lo social: las normas jurídicas pueden ser de dos tipos, legales (ex lege) y contractuales (ex contractu), así se recoge en el Código Civil español que preceptúa en su artículo 1089 que las obligaciones "nacen de la ley, de los contratos y cuasi contratos", además de añadir las obligaciones culposas (las que nacen de culpa o negligencia). Un ejemplo paradigmático de tal realidad lo tenemos en España en nuestro Derecho laboral, que incorpora como fuente de su ordenamiento jurídico -además de las leyes laboraleslos convenios colectivos, que no dejan de ser normas contractuales o pactadas, a las que el estado -el titular legítimo en el monopolio de la coercitividad jurídica- sanciona, estos pactos privados y voluntarios, con el máximo valor normativo.

Desde tiempos recientes estamos asistiendo, también, a una toma de conciencia que postula encontrar parámetros que midan no solo el tradicional y estrecho concepto de eficiencia de la empresa en términos de maximización y productividad, sino también en términos de "eficiencia social" a través del Balance social (Cuervo 2003) al tiempo que asistimos a una progresiva normativización y "presión regulatoria" (Nieto Antolín 2005) de la RSC, apareciendo regulaciones, estándares y códigos dando paso a un debate sobre su obligatoriedad o voluntariedad (Cuesta González et al. 2003 y Fernández Gago 2005) que tienen su hito inicial en el Pacto Mundial de las Naciones Unidas, seguido de directrices de la OCDE, el Libro Verde de la Unión Europea sobre el marco europeo para la Responsabilidad social de las empresas, amén de otros estándares normativos (la mayoría europeos). 
A este fenómeno universal hay que sumar la propia regulación española, desde las normas constitucionales pasando por referentes normativos en otros textos legales y la propia elaboración del Derecho que hace la jurisprudencia a través de las sentencias de los más altos Tribunales españoles: el Tribunal Constitucional y el Tribunal Supremo, e incluso de las propias normas jurídicas a través de la nueva legislación medioambiental española que está produciendo, como veremos, el derrumbe del viejo y sacrosanto principio liberal de responsabilidad por culpa para hacer emerger un nuevo principio, más social, de responsabilidad objetiva o sin causa.

En definitiva subyace a toda esta situación una cuestión nada pacífica: la vieja pugna entre desregulación-libertad de empresa (que inspiran nuestro sistema de capitalismo, ahora globalizado) y regulación (que informa los contenidos de Estado social y de bienestar, especialmente vigorosos en el espacio europeo), de esta dialéctica surgirán las soluciones futuras que, ya, los estados y las organizaciones están comenzando a anticipar.

\section{LA NORMATIVA Y LOS PRINCIPIOS INTERNACIONALES}

Las regulaciones y estándares internacionales ya han sido objeto, como anticipamos, de estudio detallado ${ }^{1}$, por lo que nos limitaremos a su sucinta descripción para encuadrar el tema con la suficiente perspectiva, sin olvidar que forman ya un corpus o acervo normativo de singular dimensión e interés y que implican una traslación normativa para los estados y empresas suscriptores de los distintos pactos.

Con un ámbito universal tenemos: Los Pactos de las Naciones Unidas y los estándares internacionales y más concretamente:

a) El Pacto internacional sobre los Derechos económicos, sociales y culturales.- Que se adoptó y abrió a la firma y adhesión por la asamblea general de la ONU en 1966. Ratificado por España en 1977, estableciendo una regulación en 31 artículos en desarrollo económico y social de la Carta fundacional de la ONU y de la Declaración Universal de Derechos. Lo más relevante a nuestro juicio es la consideración del

Respecto a este epígrafe contextualizador, existe un excelente trabajo donde se contiene la normativa internacional: R. Fernández Gago (2005) La administración de la Responsabilidad Social Corporativa, Madrid: Thomson-Civitas; y más concretamente el capítulo 2 en el que describe detalladamente El Pacto Mundial, las Directrices de la OCDE, el Libro verde de la Unión europea, la Comunicación de la Unión europea sobre RSC y los diversos foros e iniciativas interempresariales. 
incuestionable valor normativo que para los estados miembros, España incluida, al ser un tratado cuyo instrumento se ha ratificado y por tanto se ha incorporado como norma jurídica al Derecho nacional.

b) El Pacto Mundial (The Global Compact).- $\quad$ El Pacto de las Naciones Unidas, tiene una vida relativamente corta, gestado bajo la Secretaria General de Kofi Annan alcanzó su concreción en el año 2000 con el objetivo de promover el desarrollo sostenible y la responsabilidad social, tratando de incorporar al mismo a empresas líderes. La primera idea fundamental es que carece de valor normativo, no se trata de un instrumento regulador. A ese objeto las N.U. crearon una oficina del pacto mundial, con sede en Nueva York, a cuyo frente está un Chief executive Officier, en su organigrama se integran el Alto comisionado de las N.U. para los Derechos Humanos, La Organización internacional del Trabajo (OIT) y los programas de Desarrollo y Medio Ambiente las propias N.U. El Pacto Mundial formula 10 principios que se nutren de tres vías normativas fundamentales que a su vez son tres declaraciones derechos (la Declaración Universal de Derechos Humanos, la Declaración sobre principios de orden laboral de la OIT y la Declaración de Río sobre Medio Ambiente y desarrollo sostenible. De los 10 principios que se formulan en el Pacto Mundial, 2 son en materia de Derechos humanos, 3 en materia de medio ambiente y un $10^{\circ}$ principio, y esto resulta lo más novedoso, en materia de corrupción (interdicción de la corrupción, extorsión y sobornos).

Tabla 1a. Empresas y entidades españolas que han suscrito el PACTO MUNDIAL. 2005

\begin{tabular}{|l|c|}
\hline Empresas & Número \\
\hline Grandes empresas & 108 \\
\hline ONGs y otras asociaciones & 70 \\
\hline Universidades e instituciones educativas & 22 \\
\hline Asociaciones sindicales y patronales & $4^{2}$ \\
\hline \multicolumn{1}{|c|}{ TOTAL } & 204 \\
\hline
\end{tabular}

Fuente: Oficina en España del Pacto Mundial - www.pactomundial.org / fecha toma de datos 14-VI-2005 Elaboración propia.

Evidentemente estas prescripciones alcanzan dimensión normativa entre las empresas que se suscriben al pacto (ex contractu), y

2 Entre ellas las dos organizaciones sindicales más representativas de implantación nacional (UGT y CCOO) y la organización patronal nacional CEOE-CEPYME, además de CEIM, la patronal de Madrid. 
también resulta palmario que estos principios tienen un carácter de Corpus mínimo que de lege ferenda es susceptible de ampliación.

Tabla 1b. Empresas y entidades españolas que han suscrito el PACTO MUNDIAL. 2006

\begin{tabular}{|c|c|}
\hline Empresas & Número \\
\hline Grandes empresas & $181^{3}$ \\
\hline Empresas & 149 \\
\hline Universidades e instituciones educativas & 25 \\
\hline Asociaciones sindicales y patronales & $13^{4}$ \\
\hline $\begin{array}{ll}\text { TOTAL } \\
\end{array}$ & 363 \\
\hline
\end{tabular}

Fuente: Oficina en España del Pacto Mundial - www.pactomundial.org / fecha toma de datos 15-VI-2006. Elaboración propia.

En las tablas (1a y $1 \mathrm{~b})$ se aprecia el incremento de adhesiones españolas al Pacto Mundial durante el último año.

c) The Global Reporting Initiative (G.R.I) y los otros estándares.- Desde finales del siglo XX (iniciada en 1997) se halla constituida esta institución independiente y no gubernamental, pero participada por las N.U a través de su programa de medio ambiente, cuyo objeto fundamental es proporcionar ítems de soporte para la elaboración de Memorias y Directrices en materia de RSC. Las directrices que han emanado del GRI le han convertido en el gran estándar mundial. Además de elaborar complementos sectoriales y protocolos técnicos. Otras iniciativas y asociaciones en materia de estándares con pretensiones igualmente universales, algunos desde una perspectiva interempresarial como es la WBCSR (World Business Council of Sustainable Development) participada por casi dos centenares de empresas internacionales. Otros, en cambio, se configuran como un modelo asociativo más amplio, como la SAI (Social Accountability International), organización no gubernamental en materia de Derechos humanos y que ha elaborado una de las normas estándar más universalmente aceptadas, la SA8000, que ofrece la posibilidad de verificación del cumplimiento de normas de Derechos Humanos, de la OIT y de diversas convenciones de Derechos.

\footnotetext{
3 Con abundantes incorporaciones de Cajas y Bancos sobre todo.

4 Incorporándose otras patronales (Valencia, Segovia, Orense), alguna Cámara de Comercio y la Asociación Nacional de Directivos y ejecutivos.
} 
La responsabilidad social corporativa. Su dimensión normativa: implicaciones para las empresas españolas

tenemos:

Con ámbito regional, más circunscrito a Europa y Occidente,

a) Las directrices de la OCDE. El área occidental.- La Organización para la Cooperación y el Desarrollo Económico (OCDE) también ha jugado un papel en la contribución a la normativización de la RSC que se formulan como líneas directrices a las que se encuentran adheridos los 30 miembros que constituyen la organización, mas otra decena de no miembros. La concreción de ese estatuto se articula en 11 directrices, que en algunos casos son una mera transposición de los principios del Pacto Mundial, con la muy significativa directriz final (la 11) que prohíbe la ingerencia en las actividades políticas locales.

En el estricto ámbito Europeo, la Unión Europea, se ha convertido en el más avanzado escenario de integración político-económica del mundo, configurándose como una asociación de países que han sido capaces de delegar cuotas de su soberanía en instituciones comunes, fundamentalmente la Comisión y el Parlamento europeo, y que, en algunos casos, sus declaraciones dejan de tener un carácter de recomendación deontológico para adquirir evidente rango normativo. Aquí reseñaremos:

b) La Constitución Europea.- Herencia de los Tratados constitutivos.- $\quad$ La Unión Europea posee una Carta o estatuto normativo básico, que primero desde su fundación en el tratado de Roma era su "norma normarum", su texto constitucional, suscrito mediante el instrumento de tratado por los países miembros y por ende directamente incorporado a la legislación de los estados miembros a través de sus instrumentos ratificatorios. Tratado que sucesivamente se fue modificando a través del Acta Única de Luxemburgo de 1986 y el Tratado de Maastrich de 1995 y de Amsterdam hasta llegar a la actual Constitución Europea, aprobada por los 25 estados miembros pendiente ya solamente de los respectivos -y en algunos casos accidentados- procesos de ratificación nacionales y ratificada, ya, por el reino de España el 20 de febrero de 2005.

Dentro del desarrollo normativo de este extenso texto constitucional se recogen artículos que orbitan en torno a dos conceptos fundamentales asumidos por los estados miembros, por un lado el fundamento propio de los estados de derecho de la Libertad de empresa (art. II, 76 del Tratado), pero al mismo tiempo se establecen límites a la misma. En consonancia con los otros principios normativos provenientes del Estado social de Derecho, estableciendo como límite a la misma "el 
derecho de la propia Unión", lo que abre la vía normativa para introducir con rango normativo, entre otras, las cuestiones de RSC. Abierta esta vía futura se regulan no obstante tres aspectos dentro del ámbito normativo que puede ser la RSC:

- "El desarrollo sostenible y la protección del medio ambiente" (art. II, 97)

- "La protección del consumidor" (art. II, 98)

- "La ayuda humanitaria a terceros países" (art. III, 321)

Estas normas serán directamente aplicables en los estados miembros y pasan sin necesidad de "transpolación" (mecanismo jurídico para incorporar como norma de derecho nacional la legislación de la Unión a la legislación nacional, creando una norma estatal) a formar parte del sistema normativo de los estados una vez ratificada la Constitución -caso español-. Evidentemente todas ellas precisarán de desarrollo reglamentario y jurisprudencial, por ejemplo el caso de la protección de consumidores, del que ya existe amplio corpus normativo en España. Pero, con todo, ya son normas directamente aplicables en cualquier caso. Por poner un ejemplo práctico con el actual derecho español e invocando el artículo II, 97 de la Constitución europea, sí una empresa realizase vertidos contaminantes que degradan el medio ambiente de su entorno, con la invocación combinada del precepto europeo y la del art. 1902 del Código Civil, de culpa extracontractual con una mera relación causal (obligación de reparación del daño causado), unos supuestos stakeholders afectados (los vecinos, un productor agrícola) podrían conseguir que se sustanciase a su favor una acción de responsabilidad contra la empresa que degrada el medio ambiente en el ejemplo clásico que en su día formuló Coase $(1937,1960$ y 1988).

c) El Libro Verde.- Independientemente de la obligada consideración normativa anterior, la estricta cuestión de la articulación positiva por parte de la Unión Europea en materia de RSC, se gesta en la cumbre de Lisboa de 2000, materializándose en el Libro Verde que redacta la Comisión europea en 2001. Desde una perspectiva aplicativa y práctica por parte del Derecho de la Unión y del de cada Estado miembro hay que situar el Libro Verde como un instrumento jurídico aplicativo: algo más que una mera declaración de intenciones y algo menos que una norma jurídica de carácter positivo, pero que en un sistema jurídico como el español o los de tipo continental tiene efectos jurídicos como fuente 
La responsabilidad social corporativa. Su dimensión normativa: implicaciones para las empresas españolas

del Derecho conforme a lo que preceptúa el art. 1,4 del Código civil, ya que al establecer el rango de las normas jurídicas se jerarquizan como leyes, costumbres y principios generales del Derecho, y en este sentido como documento normativo de la Comisión son Principios del Derecho, es decir la interpretación auténtica que la Comisión confiere a los mismos.

d) Iniciativas de estandarización en Europa. Normativa ínter empresarial.- Junto a las iniciativas internacionales que someramente examinamos al final del epígrafe anterior en el ámbito regional europeo se ha constituido como asociación la CSR (Corporate Social Responsibility) europea, que asume y traslada los principios de la WBCSR y la SAI, configurando sus propios estándares que operan como Bench marks susceptibles de incorporarse a los Balances sociales de las empresas.

\section{LA NORMATIVA ESPAÑOLA}

El caso español integrado en el espacio regional de la Unión Europea, y que, por ende, asume las normativas, postulados y formulaciones someramente descritas hasta aquí, presenta una serie de singularidades que merecen un estudio detallado, articulando, ya, un muy eficiente sistema de protección jurídica de los principios de RSC.

\subsection{Los preceptos constitucionales: Los principios normativos}

La dimensión social de la empresa en Europa tiene su reflejo normativo en las respectivas normas que ocupan el peldaño jerárquico superior del sistema normativo, las Constituciones de los estados que postulan su naturaleza como "Sociales" y de "Derecho". Cartas magnas que se han gestado en el viejo continente, en un largo iter que se inicia al final de la Segunda Guerra Mundial (1945-1990), y entre las que la española de 1978 es un buen, aunque tardío, paradigma que incorpora al estado de Derecho el nuevo adjetivo de "social": "Estado social y democrático de Derecho", tal como reza el artículo primero de nuestra Carta Magna.

En consecuencia se asumen esos principios éticos y sociales en los "Principios rectores de la política social y económica" y por ende a la regulación pormenorizada de la empresa, como en el art. 38 que reconoce la libertad de empresa, pero que subordina a "las exigencias de la economía general y en su caso de la planificación"; o la más genérica 
disposición del artículo 45,2 del mismo texto legal que estatuye que los poderes públicos "velarán" por la utilización racional de los recursos naturales "apoyándose en la indispensable solidaridad colectiva". Postulaciones, ambas, que entran en la misma entraña del concepto de RSC. Trasunto que, como vimos, se encuentra recogido en la nueva Constitución Europea.

\subsection{Legislación administrativa y mercantil. Proyectos} normativos. Su impacto jurídico-económico

La Legislación empresarial, fundamentalmente el código de Comercio y la Ley de Sociedades Anónimas, responde a las viejas formulaciones liberales del derecho mercantil, aún no ha incorporado preceptos modificatorios que amparen la presión normativa que estamos describiendo para una explícita consideración de la RSC. Pero si que comienza a apreciarse desde los años 80 en otro tipo de normativas más híbridas, a caballo entre la normativa mercantil y la administrativa, como es por ejemplo la Ley de Consumidores y usuarios. Ley $26 / 84$, concebida y desarrollada, tal como se expresa en su preámbulo, en desarrollo del art. 51 de la Constitución con capítulos de título tan significativo como "La protección de los intereses económicos y sociales" (cap. 3) o "Situaciones de inferioridad, subordinación o indefensión" (cap. 7). Texto que se contiene en 41 artículos y 4 disposiciones finales.

Legislación, ésta, en materia de protección de los Consumidores, que se ha desarrollado territorialmente en prácticamente todas las Comunidades autónomas, 15 hasta la fecha. Con extensísimas y pormenorizadas regulaciones en algunas de ellas, entre las que sobresale la andaluza con un muy extenso articulado (100 artículos) y con muy significativos epígrafes como "Derecho de protección de la salud y seguridad" (cap. 3, artículos 6 al 9) o "situaciones de inferioridad de los consumidores" tales como desventaja del mercado, por edad, por desigualdad como empresa, hechos que entran de lleno en una filosofía regulatoria al reconocer la fáctica desigualdad de condiciones y asimetrías de información y recursos en un mercado imperfecto (cap. 9, arts. 36-37). En la tabla siguiente se contienen las respectivas legislaciones autonómicas: 
Tabla 2. Legislación de Defensa de Consumidores y usuarios en España

\begin{tabular}{|l|l|l|l|}
\hline Carácter- Ámbito & Territorio & Denominación & Fecha \\
\hline ESTATAL & España & Ley 26/84 Defensa de Consumidores y usuarios & $9 / 7 / 1984$ \\
\hline AUTONÓMICO & Galicia & Ley 12/84 & 1984 \\
\hline AUTONÓMICO & C. Valenciana & Ley 2/87 & 1987 \\
\hline AUTONÓMICO & Navarra & Ley 3/95 & 1995 \\
\hline AUTONÓMICO & Extremadura & D.L. (Decreto Ley) 44/95 & $18 / 4 / 1995$ \\
\hline AUTONÓMICO & Murcia & Ley 4/96 & 1996 \\
\hline AUTONÓMICO & Aragón & Ley 8/97 & 1997 \\
\hline AUTONÓMICO & Cantabria & Ley 6/98 & 1998 \\
\hline AUTONÓMICO & Madrid & Ley 11/98 & 1998 \\
\hline AUTONÓMICO & Castilla y León & Ley 11/98 & 1998 \\
\hline AUTONÓMICO & Baleares & Ley 11/98 & 1998 \\
\hline AUTONÓMICO & Asturias & Ley 11/ 02 & 2002 \\
\hline AUTONÓMICO & Canarias & Ley 3/03 Estatuto de consumidores y usuarios & 2003 \\
\hline AUTONÓMICO & Andalucía & Ley 13/03 & 2003 \\
\hline AUTONÓMICO & Euskadi & Ley 14/03 Estatuto de personas consumidoras y usuarias & $22 / 12 / 2003$ \\
\hline
\end{tabular}

Fuente: Elaboración propia.

Esta normativa se ha ido desarrollando en 3 fases: 1) con carácter estatal a mediados de la década de los 80 , inicio de desarrollo autonómico, en las mismas fechas. 2) Desarrollo autonómico generalizado en la segunda mitad de la década de los 90. Y 3) últimos desarrollos extensos desde el año 2002.

Resta añadir una importante mención a una legislación muy reciente que habrá de producir -por sí y por su normativa de desarrolloun evidente impacto jurídico-económico en las empresas la Ley 1/2005 de 9 de marzo de "Régimen de Comercio de derechos de emisión de gases de efecto invernadero", que va a conllevar, de lege ferenda, cambios muy sustantivos. En el momento de redacción de este artículo se está desarrollando como anteproyecto de ley, de la que será la futura Ley de Responsabilidad civil medioambiental, que articula una concepción de Responsabilidad objetiva, sin culpa en base al principio de "quien contamina paga" que asume el art. 130R del Acta única europea. Así reza el art. 3,1 del anteproyecto: "La responsabilidad civil regulada en esta ley es objetiva y será exigible con independencia de que exista culpa o negligencia en el responsable" con lo que el secular principio que en especial en el ámbito de la empresa y del Derecho mercantil existía por responsabilidad civil (siempre causal) se derrumba ante el más alto interés general y social de proteger el medio ambiente. Otro aspecto es la atribución de capacidad procesal (legitimación activa en derecho) a toda la colectividad a través del art. 5b del anteproyecto que posibilita el inicio de la acción por las organizaciones no gubernamentales y ecologistas. 


\subsection{Jurisprudencia}

Careciendo de la importancia normativa y protagonismo que tiene en el derecho anglosajón de la Common Law, entre los derechos continentales europeos, la jurisprudencia -es decir la doctrina autorizada que sientan los tribunales en la interpretación del Derecho- constituye una fuente más del Derecho desde la tradicional interpretación de la pirámide kelseniana, reconocida palmariamente en el sistema normativo español, a través del art. 1.6 del Código Civil, que sitúa a la Jurisprudencia como fuente del Derecho en tercer lugar entre la jerarquía normativa tras la ley y la costumbre del derecho. En cualquier caso y con una dimensión que ya ha sido señalada, la jurisprudencia constituye un auténtico "nicho" de interpretación para juristas y economistas (Mercuro \& Medema 1999).

En el Derecho español dos jurisprudencias autorizadas han de ser contempladas la del Tribunal Supremo, como interprete autorizado del Derecho ordinario a través de los Recursos de Revisión y de Alzada, y la del Tribunal Constitucional (Recursos de Inconstitucionalidad y de Amparo), como jurisdicción en materia de interpretación de las normas constitucionales y de los Derechos fundamentales dentro de los cuales se incardinan tanto el principio de Libre empresa como el de los Derechos sociales de carácter individual y colectivo.

\section{a) Jurisprudencia del Tribunal Supremo}

Del análisis de ambas jurisprudencias, y en especial de la del Tribunal Supremo (TS), podemos colegir que ya se está iniciando una jurisprudencia que puede ser invocada en los tribunales en materia de RSC, conexa con los principios de Responsabilidad civil, a la que se está dando un giro objetivo abandonando el nexo causal, de forma que el efecto del daño (un vertido contaminante, unas secuelas colectivas...) genera la responsabilidad independientemente de la voluntad o negligencia del causante del daño. Y todo ello previamente a la plasmación de estos principios en la reciente normativa de daños medioambientales a la que acabamos de referirnos en el epígrafe anterior.

Un ejemplo evidente lo tenemos en los más recientes pronunciamientos del Tribunal Supremo sobre la Ley de Consumidores y usuarios (L. 26/84 antes citada) en sentencia del 10 de junio de 2002 (ponente Sr. García Varela), en que hablando de la responsabilidad de la empresa y del empresario, al afirmar que la responsabilidad se deriva "no 
solo de las disposiciones reglamentarias... sino de la diligencia (del empresario), de la esencia y de las características del producto...", dándose una "responsabilidad objetiva" y respondiendo el empresario "por el riesgo creado", en el mismo sentido se pronuncia otra sentencia TS, sala 2, 11-V1999 (ponente Sr. Martínez Calcerrada) respecto a la responsabilidad en una compraventa al seguir otro principio de responsabilidad objetiva, desplazando la responsabilidad del vendedor al fabricante: "el vendedor no responde de los vicios propios de la cosa... ha de hacerse responsable al el fabricante". En esta línea jurisprudencial interpretativa se sienta el principio de que la única exclusión de responsabilidad para el empresario (fabricante o vendedor); y únicamente es "la culpa exclusiva de la víctima" la única causa que impide el nacimiento del derecho a indemnización (Sentencia TS, Sala 2a , 24-IX-2002, ponente Sr. Romero Lorenzo, también en materia de interpretación de la Ley General de Consumidores y Usuarios L. 26/84). Criterio de responsabilidad objetiva del empresario que vuelve a recogerse inequívocamente en otra sentencia de TS de 10 de junio de 2002 en materia de garantías y responsabilidades de consumo (ponente Sr. García Varela) en que se vuelve a insistir en la responsabilidad objetiva, tan esclarecedora que merece una larga cita:

\begin{abstract}
... la exigencia de observar no solo las prescripciones reglamentarias, sino también los demás cuidados y diligencias que exige la naturaleza del producto. Si bien no requiere la plasmación de una diligencia exorbitada, si que se impone extremar las diligencias correspondientes a la propia esencia y características del producto con una responsabilidad objetiva o responsabilidad por el riesgo creado: el criterio de imputación de responsabilidad es el hecho de que el consumidor sufra un daño, sin que sea preciso que haya mediado, o no, negligencia del fabricante.
\end{abstract}

\title{
b) Jurisprudencia del Tribunal Constitucional
}

La jurisprudencia del más autorizado interprete de la Constitución, el Tribunal Constitucional -para algunos una suerte de "superjurisdicción" a la que se recurre en asuntos de enjundia una vez agotada la vía judicial ordinaria (García de Enterría 1981: 60-61 y 66)-, también se alinea, al igual que el Tribunal Supremo, en la posición doctrinal de atribuir competencias al Estado en materia de intervención de actividades de las que se puedan derivar perjuicios a terceros innominados (externalidades negativas en términos económicos). 
En este sentido ya existen pronunciamientos y sentencias desde los momentos iniciales de funcionamiento del Tribunal Constitucional, tal es el caso de la Sentencia 52/88, BOE $n^{\circ} 89$ de 4 de abril de 1988, con ponencia del magistrado Carlos de Vega Benayas, donde se debatía, en un recurso de inconstitucionalidad los límites estatutarios de una comunidad autónoma (en este caso la Generalitat de Cataluña) respecto a la regulación de normas de homologación y fabricación de productos, analizando los artículos 139,1 y 139,2 de la Constitución respecto a la libre circulación de personas y Bienes, competencia exclusiva del Estado. El argumento que más nos interesa respecto al pronunciamiento del Tribunal Constitucional es el recogido en el fundamento jurídico $3^{\circ}$ de la Sentencia, en que si bien reconocía y atribuía a la Generalitat la potestad para regular la fabricación y homologación de productos, señalaba que esta potestad debía estar "limitada por los principios de igualdad y libre circulación"; ya que a tenor del artículo 149,1 de la Constitución, es competencia exclusiva del Estado la regulación de las condiciones básicas que garantizan la igualdad de todos los españoles, de forma que se declaraban inconstitucionales algunos preceptos que suponían una ruptura con el principio general y social reconocido de igualdad y Libre circulación.

Mucho más explícitas son sentencias recientes, como la 109/2003 (ponente D. Tomás S. Vives Antón), sobre un conflicto de competencias promovido por el gobierno de la Nación contra la Comunidad de Castilla la Mancha a propósito de la regulación de productos farmacéuticos, recurso que a la postre declararía nulos algunos preceptos del reglamento castellanomanchego. El argumento en torno al cual gira todo el debate jurídico, no es otro que el mismo en torno al cual se realiza toda nuestra reflexión de los aspectos regulativos de la RSC: cuando en pugna, los principios de "libre empresa" debe ceder ante los más altos y sociales del "interés general"; en este sentido en la sentencia referida se alude -y citamos literalmente- a "la libertad de empresa y propiedad privada, de un lado, y el interés público y la planificación pública, de otro..." (Preámbulo), para concluir, respecto al sector farmacéutico, que "queda sometido a la obligación de prestar una serie de servicios básicos a la comunidad" y tratarse, en el caso de las farmacias, de establecimientos públicos "sujetos a la planificación sanitaria". Similar planteamiento, y resolución, tuvo el Recurso de inconstitucionalidad que se entabló, también por el gobierno de la nación, contra la Comunidad de Extremadura sobre la misma cuestión. 
Fig. 1: Cuadro de protección de la RSC en España

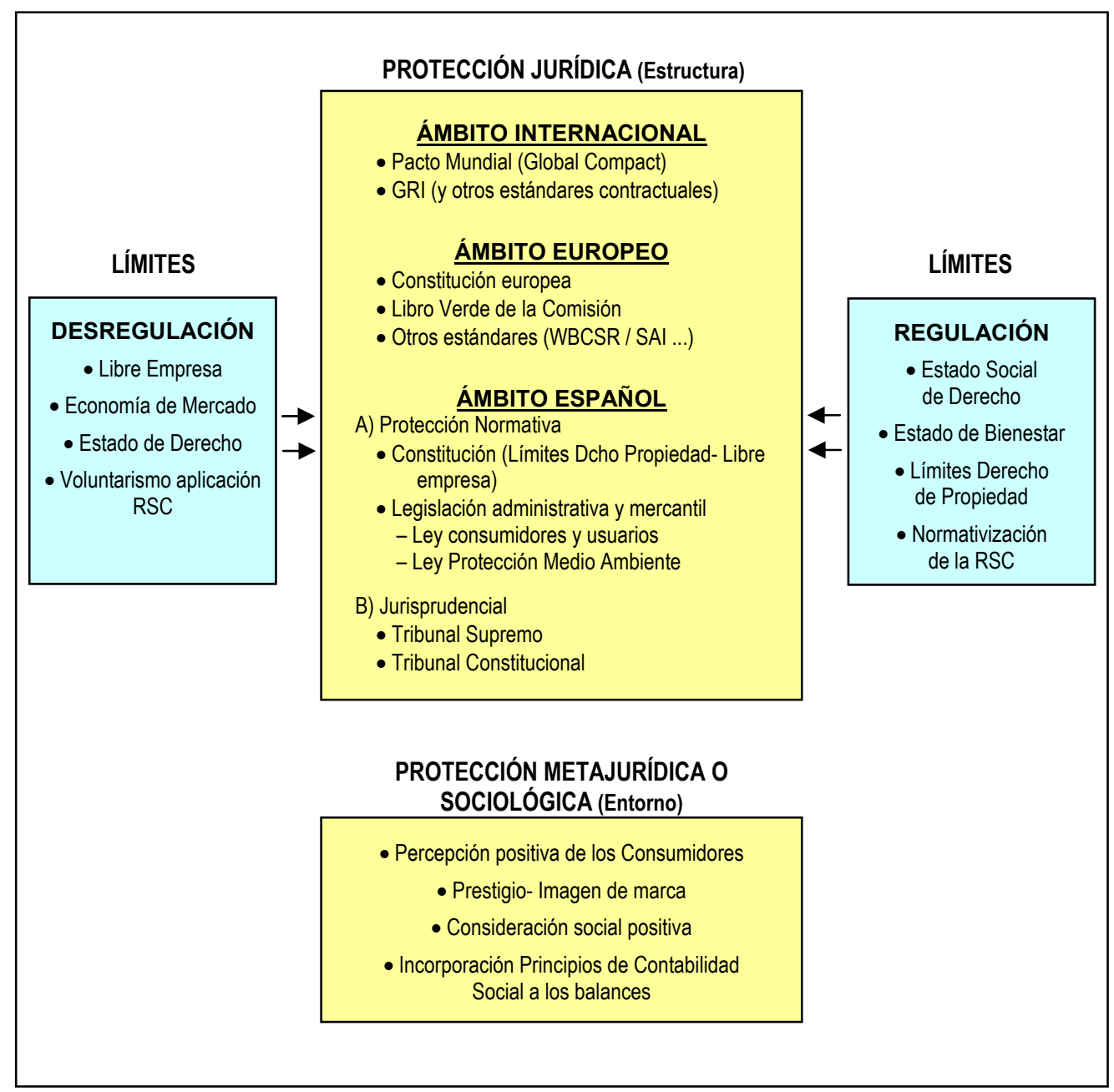

Fuente: Elaboración propia.

Otro de los temas nucleares en torno a los que orbita la RSC y que se destilan en los principios jurisprudenciales del alto tribunal son los relativos a medio ambiente, así en sentencia 16/2004 de 23 de febrero de 2004, con ponencia del magistrado Manuel Jiménez de Parga en que se debatía una sanción impuesta por el ayuntamiento de Gijón a una empresa por contaminación, el Tribunal denegó el amparo solicitado por el empresario recurrente y confirmó la sanción invocando el reglamento de actividades insalubres y la ley de protección del Medio ambiente. Similar planteamiento de protección a terceros ajenos a la empresa o a la titularidad privada de las propiedades afectadas se deriva del conflicto de 
competencias que se entabló entre el estado y la Comunidad de las Illes Balleares que señala como compendia exclusiva del Estado cuando se trata de un Espacio Natural que debe exigir el "pacífico disfrute del interés general nacional" a todas las personas (Sent. 97/2002 de 22 de mayo de 2002).

Evidencias, todas las que hemos narrado, que nos permiten constatar, especialmente en los tiempos más recientes, como la jurisprudencia española está asumiendo criterios y principios de RSC en la resolución de conflictos públicos y privados, que, desde luego trascienden tanto relaciones contractuales como de propiedad privada.

\subsection{La protección y la tutela metajurídica o sociológica}

Junto a toda esta protección normativa descrita de la RSC en España, a través de los preceptos constitucionales, la legislación administrativa y mercantil (Leyes de protección de los Consumidores y de protección del Medio Ambiente) y la jurisprudencia, existe otra, no desdeñable, y es la que la propia sociedad confiere a través de los consumidores y de las propias empresas, y cuyos efectos, tienen más que ver más con la consecución de una ventaja competitiva en términos de reputación que con los costes privados.

Por parte de los consumidores, por la percepción positiva que tienen de la empresa "socialmente responsable", lo que favorece su propensión a consumir sus productos en términos de igualdad de Coste, aunque, eso sí, con distintas incidencias geográficas como demuestra el reciente estudio de Bigné et al. (2005).

Por parte de las empresas, en términos de reputación y de consecución de una ventaja competitiva, que supone asumir e internalizar parte de los costes sociales en sus balances (Porter y Kramer 2002). Si bien es cierto que la incorporación de criterios de RSC debe hacerse desde una perspectiva estratégica e integradora para no generar una "pernicious CSR" tal como críticamente se representa en la fig. 2. 
Fig. 2: Cuadro de acción de RSC. Perspectiva crítica

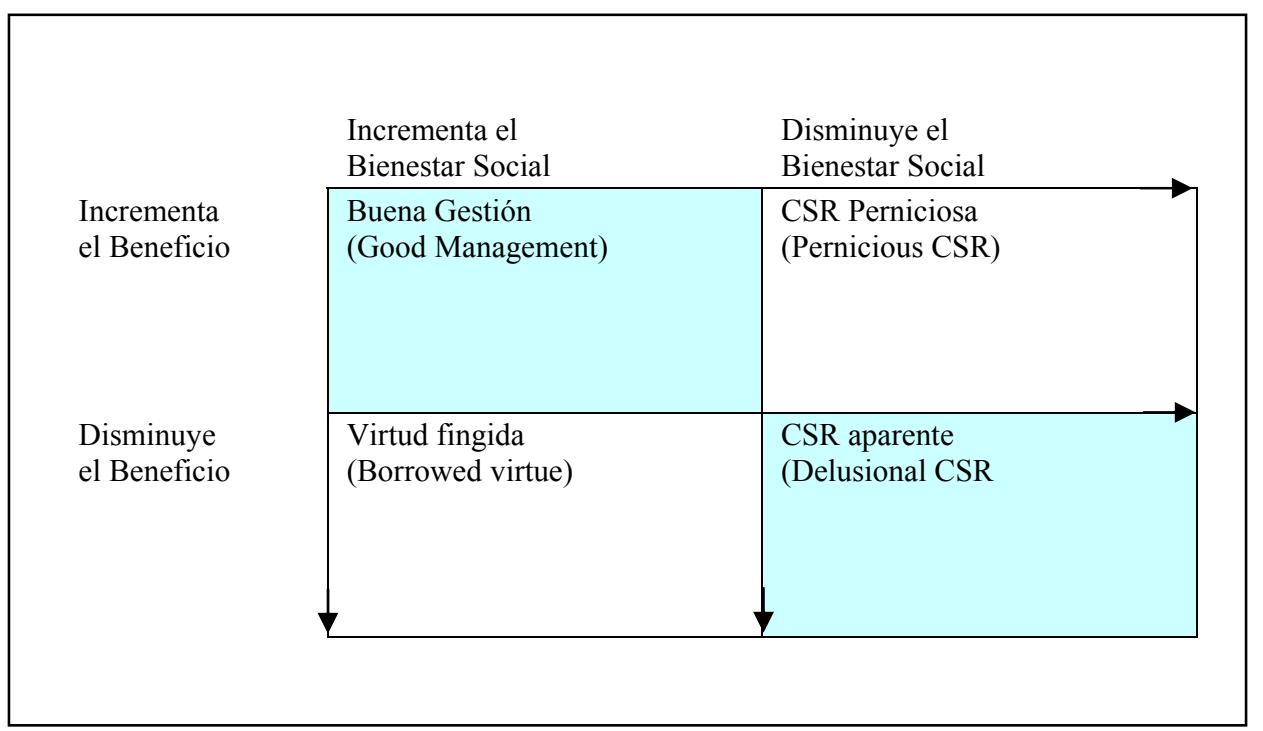

Fuente: The Economist, 22, 2005, p. 7.

4. COROLARIO: IMPLICACIONES ECONÓMICAS DE LA REGULACIÓN DE LA RSC

Del somero análisis que precede, hoy estamos en condiciones de concluir que junto a las normas de aplicación voluntaria por parte de las empresas en materia de RSC (en todo occidente en general, con especial incidencia en Europa, y en el caso español muy en particular) se está generando todo un Corpus jurídico (legal y pactado) que paulatinamente está cristalizando en dimensiones normativas e interpretativas por parte de los creadores y aplicadores del Derecho. De todo ello un ejemplo emblemático es la nueva legislación medioambiental a través de la ya vigente ley 1/2005 de "Régimen de Comercio de derechos de emisión de gases de efecto invernadero" y el texto legal ya como anteproyecto de Ley de responsabilidad civil medioambiental. Las implicaciones económicas para la sociedad y para la empresa son de lo más sustantivas, en definitiva todo este fenómeno se puede analizar bajo el paraguas teórico de los Costes de transacción (Coase 1937, y en España Arruñada 1990).

La más obvia implicación económica de este cambio institucional emergente es que se imponen unos nuevos costes de 
transacción a la empresa para evitar perjuicios globales y colectivos, tratando de igualar el coste privado marginal, el de la empresa, con el coste marginal social, el de la sociedad; por ejemplo en el caso de vertidos y daños medioambientales (Coase 1960) utilizando un análisis más nuevo (Mercuro \& Medema cit.), tal como se refleja en la figura $n^{\circ} 3$.

Fig. 3: Coste Marginal privado y Coste Marginal Social con una nueva legislación medioambiental

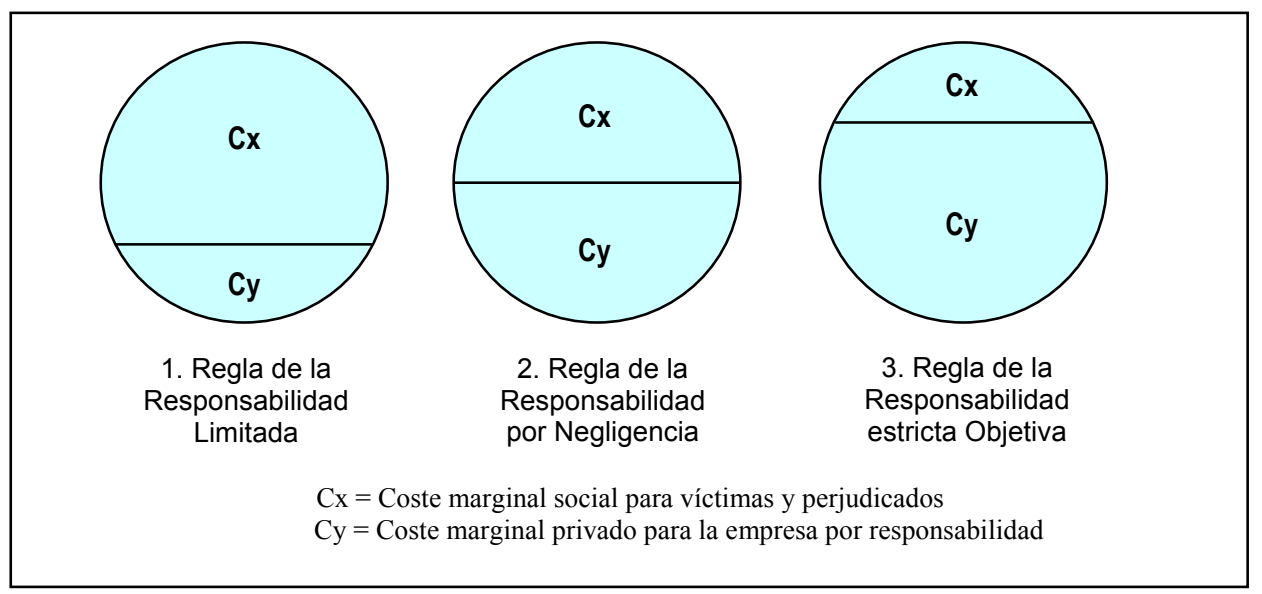

Fuente: MERCURO \& MEDEMA, 1999, pp. 70-72.

(El ejemplo lo utilizan para una nueva normativa de señalización en prevención de los accidentes de tráfico, pero es perfectamente trasvasable a una nueva normativa de prevención contra la contaminación como la que nos ocupa. Con la aparición en España de la nueva Ley de Responsabilidad Medioambiental, estamos transitando hacia el tercer espacio de Responsabilidad objetiva estricta)

Respecto a un tema crucial para el análisis jurídicoeconómico de la RSC, el de la contaminación medioambiental, la cuestión ya fue planteada de forma pionera hace cuatro décadas por Coase a través de su artículo "El problema del Coste social" (Coase 1960) y casi de forma simultanea por Calabresi (1961); en su momento y para justificar el famoso teorema de Coase, que el no había formulado, pero que se deducía de sus trabajos. Coase determinó el Coste de transacción entre un propietario de una fábrica que generaba vertidos fluviales y los agricultores locales (downlanders); el empresario buscando maximizar el beneficio se planteaba si instalar, o no, un sistema de filtros, por lo que ambas partes llegarían a un acuerdo transaccional buscando maximizar sus costes. 
Hoy, tras las últimas aportaciones de Posner (1983) podremos comprender muy bien cómo se está produciendo el cambio normativo en materia de RSC, y que nos permite trasladar el silogismo que hacía Posner respecto a las decisiones eficientes de los jueces de la common law al mundo del derecho continental europeo y al caso español con un criterio de equilibrio paretiano siguiendo el modelo de eficiencia en el intercambio de Kaldor-Hicks. La decisión jurisprudencial, imponiendo costes por responsabilidad a los transgresores, altera los incentivos económicos para las firmas; del mismo modo una reforma legal como la que se está realizando en España a partir de la ley 1/2005 ya referida "incrementa el precio de la polución" (Mercuro y Medema 1999) para el empresario, haciendo que evite polucionar, al ser menos eficiente el hacerlo y tener que enfrentarse a una responsabilidad objetiva, como acontecerá con la nueva ley española de responsabilidad medioambiental, al obligarle la lógica económica a elegir el menor coste alternativo.

Justamente, éste, y no otro era uno de los problemas que plantean los detractores de la ampliación RSC: su difícil mensurabilidad en términos monetarios; mucho más soluble, en cambio, cuando emerge la responsabilidad cuantificable (tort, liability... en el ámbito anglosajón). Sin duda los costes procesales, indemnizatorios etc. son mucho más mensurables.

Regresando a la estricta perspectiva jurídica estamos en condiciones de concluir que la RSC en España tiene configurado un sistema de protección en dos ámbitos: uno jurídico (vid. fig. 1) y otro de no menor importancia metajurídico o sociológico, ambos con evidente traslación económica, al obligar a las empresas, en virtud del aumento de la presión normativa a ir internalizando Costes sociales en la forma descrita.

La forma en que habrán de afrontar las empresas esta nueva realidad será conciliando la eficiencia y la RSC, haciendo de las empresas organizaciones con una "mayor densidad de relaciones con el entorno" -por utilizar la terminología de Cuervo (2003)-. Las empresas más pioneras y socialmente responsables habrán de ocupar nuevos espacios, el espacio $B$ de la fig. siguiente: 
Fig. 4: Eficiencia y Responsabilidad Social de la Empresa

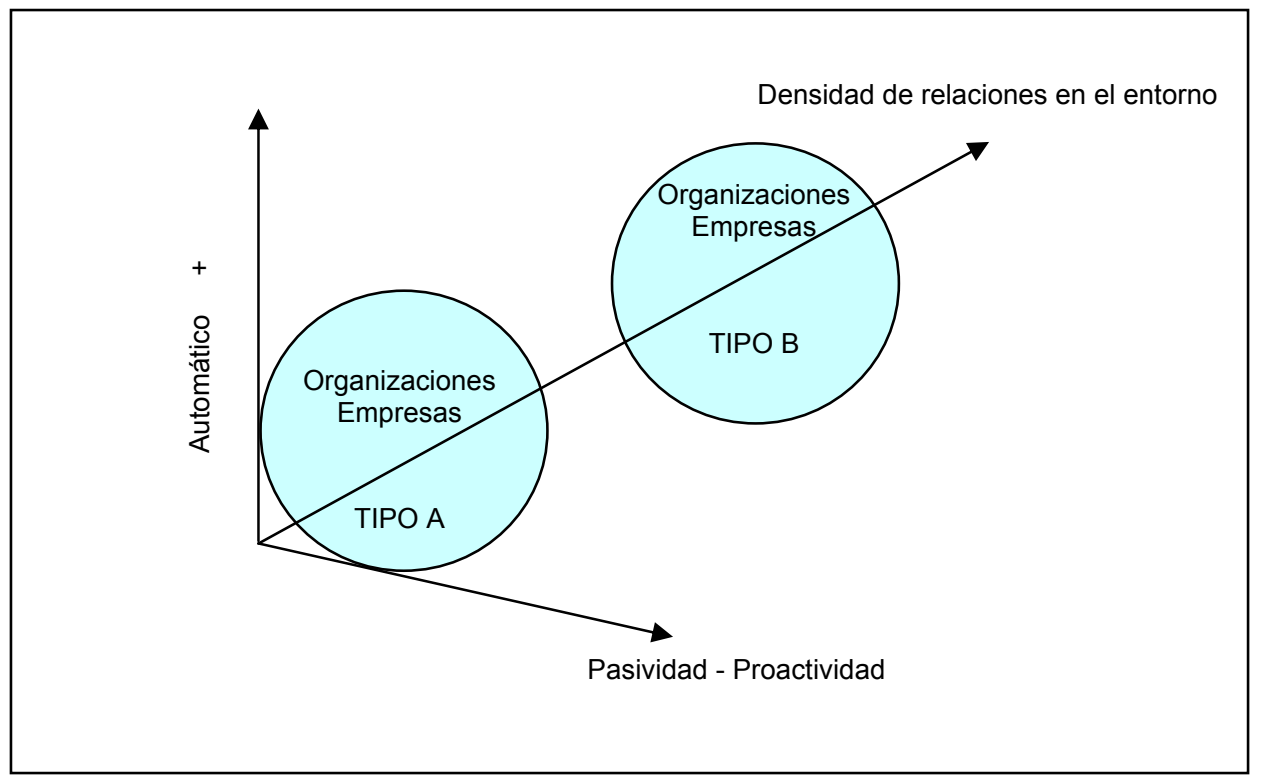

Fuente: A. Cuervo, 2003, p. 119

Implicaciones, todas ellas, jurídicas y económicas para las empresas, que habrán de asumir los nuevos parámetros normativos y sociológicos. A la postre, el secreto, para las mismas, estará en percibir esa interacción de la empresa y del entorno en que se encuentra inmersa y calibrar sus consecuencias respecto a una redefinición del Coste Social y del Coste privado, integrándolos, de forma que, aún internalizando costes sociales, se deriven ventajas competitivas. Caminando, en definitiva, hacia una nueva reformulación, más amplia, social y globalizadora del propio concepto de la empresa.

\section{BIBLIOGRAFÍA}

ARrow, K.J. (1973) "Social Responsibility and Economic Efficiency", Public

Policy Fall, vol. XXXI, n 3, pp. 303-317.

ARRUÑAdA, B. (1990) Teoría contractual de la empresa. Barcelona: Ariel.

BIGNÉ, E. et al. (2005) "Percepción de la Responsabilidad Social Corporativa: un análisis Cross-cultural", Universia Business Review, Primer trimestre, 5, pp. 14-27. 
La responsabilidad social corporativa. Su dimensión normativa: implicaciones para las empresas españolas

CALABRESSI, G. (1961) "Some Thoughts on Risk Distribution and the Law of Torts", Yale Law Journal, marzo, pp. 499-553.

CARTER, C.R. \& JenNingS, M.M. (2002) "Logistics Social Responsibility: An integrate framework", Journal of Business Logistics, 23, pp. 145-180.

COASE, R.H. (1988) The Firm, The Market and the Law. University of Chicago Press (edición española: La Empresa, el Mercado y la Ley. Alianza, 1994).

- (1937) "The nature of the Firm", Economic, 4, pp. 386-405.

- (1960) "The problem of the Social Cost", The Journal of Law and Economics, 3, pp. 1-44.

Cuervo, A. (2003) "Eficiencia y responsabilidad social de la empresa", Liber Amicorum: Economía, empresa y trabajo: Homenaje a Manuel Alonso Olea. Madrid: Thomsom-Civitas, pp.101-123.

CUESTA GONZÁlEZ, M. et al. (2003) "Promoción institucional de la Responsabilidad Social Corporativa. Iniciativas internacionales y nacionales", Boletín Económico ICE, 2775, pp. 9-20.

FERNÁNDEZ Gago, R. (2005) Administración de la Responsabilidad Social Corporativa. Madrid: Thomson.

GaRCíA DE ENTERRÍA, E. (1981) La Constitución como norma y el tribunal Constitucional. Madrid: Civitas.

MARGOLIS, J. \& WALSH, J.P. (2003) "Misery loves Companies: Rethinking Social Initiatives by Business", Administrative Science Quarterly, 48, pp. 268-305.

Mercuro, N. \& Medema, S.G. (1999) Economics and the Law. From Posner to Post-Modernism. Princeton University Press, 1997 (3ª , 1999).

Nieto Antolín, M. (2005) "¿Por qué adoptan criterios de R.S.C. las empresas españolas?", Economistas, enero, pp. 253-259.

- \& FERNÁNDEZ GAGO, R. (2004) "La responsabilidad social corporativa, la última innovación en management", Universia Business Review, 1 trimestre, pp. 28-40.

Porter, M.E. \& KRAMER, M.R. (2002) "The competitive advantage of Corporate Philanthropy", Harvard Business Review, 80, pp. 56-68 . Edic espñl.: "La filantropía empresarial como ventaja competitiva", Harvard Deusto Review, 112, enero-febrero 2003, pp. 7-20.

POSNer, R.A. (1998) El análisis económico del Derecho. Mexico: Fondo de Cultura Económico.

SteRnBerg, W. (2003) Just Business. Oxford University Press.

The Economist (2005) The good company. A Survey of Corporate Social Responsibility, enero. 